REVISTA DE LITERATURA E CULTURA RUSSA

\title{
Ostraniénie e a pedagogia de Eisenstein
}

\section{Ostraniénie and Eisenstein's pedagogy}

Autor: Erivoneide de Barros

Edição: RUS Vol. 11. № 16

Data: Setembro 2020

https://doi.org/10.11606/issn.2317-4765.rus.2020.171547 


\section{Ostraniénie e \\ a pedagogia \\ de Eisenstein}

\section{Erivoneide de Barros*}

Resumo: 0 presente artigo retoma a definição do conceito de ostraniénie, de Viktor Chklósvski, a fim de explorar a sua relação com a noção de imagem artística investigada nas aulas de Direção Cinematográfica ministradas por Serguei Eisenstein no Instituto Estatal Russo de Cinema (VGIK) e as possíveis conexões desse conceito com os estudos interartes.

\begin{abstract}
This article revisits the definition of the concept of ostranenie, by Viktor Shklovsky, in order to explore its relationship with the notion of artistic image investigated in the Cinematographic Direction classes taught by Sergei Eisenstein at the Russian State Institute of Cinematography (VGIK) and the possible connections of this concept with interarts studies.
\end{abstract}

Palavras-chave: ostraniénie; Eisenstein; Chklóvski; Estudos interartes Keywords: ostranenie; Eisenstein; Shklovsky; Interarts studies 
*Doutoranda pelo programa de Pós-Graduação em Teoria e História Literária do Instituto de Estudos da Linguagem da Universidade Estadual de Campinas - UNICAMP - com bolsa CNPq (processo no 169462/2018-8), Brasil; https://orcid.org/00000003-2941-236X; erivoneidebarros@gmail.com

\section{Prólogo}

No início do século XX, as rupturas nas formas de concepção das obras artísticas impulsionaram outros modos de aproximação com os objetos oriundos das diversas linguagens. Aos fenômenos estéticos que emergiram nesse contexto, somam-se o aprimoramento do cinematógrafo e as possibilidades advindas do aparato técnico (montagem, luz, movimento, découpage) que diretamente impactaram as outras artes e seus estudos críticos e teóricos. Neste artigo, interessa-nos retomar o conceito de ostraniénie, ou estranhamento, formulado por Viktor Chklóvski (1893-1984) sob o cenário da Primeira Guerra Mundial e às vésperas das Revoluções de 1917, ${ }^{1}$ a fim de explorar uma possível relação entre a concepção de imagem artística, que surgiu a partir dos estudos chklóvskianos, e o projeto pedagógico arquitetado por Serguei Eisenstein (1898-1948).

O conceito de Ostraniénie tornou-se relevante para os estudos literários ao propor uma nova relação teórica com as obras, sendo, posteriormente, integrado às discussões sobre o conceito de "literaturidade", que, de maneira ampla, refere-se à composição de recursos estéticos que permitem caracterizar um texto como literário. Cabe ressaltar que os dispositivos explorados na concepção de ostraniénie não são aspectos rígidos, aplicáveis, pelo contrário, convertem-se em elementos mutáveis que variam de acordo com os propósitos de cada autor.

Enquanto composição de um sistema organizacional do texto, gerador de camadas significativas que integram a estru-

1 Conforme bem salienta Daniel Aarão Reis Filho, é preciso compreender a Revolução de outubro de 1917 como um processo em que a Revolução de 1905 figura na condição de prólogo e cujo auge ocorre em fevereiro de 1917 com a abdicação do tsar Nicolau Románov e o fim de sua dinastia. In: As revoluções russas e o socialismo soviético. São Paulo: Editora Unesp, 2003, pp. 41-64. (Coleção Revoluções do Século XX). 
tura artística, ostraniénie revela a heterogeneidade presente nos princípios de estruturação das formas e as consequentes nuances do processo criativo. Foi o potencial de externar um fenômeno estrutural na origem de um efeito de percepção estética que permitiu a incorporação do conceito aos estudos teóricos de outras linguagens artísticas, sobretudo o cinema.

O cinema, em sua gênese, provocou em seus primeiros espectadores uma inusitada experiência estética quando estes viram cenas do cotidiano projetadas na tela. As possibilidades advindas do aperfeiçoamento técnico ampliaram-se e exigiram uma melhor compreensão de suas potencialidades enquanto linguagem artística, assim como a indicação do lugar do cinema no sistema das artes. Os atributos da cinematografia exigiram dos pensadores da época uma espécie de resposta teórica no que diz respeito à ideia de percepção nas artes. Foi nesse contexto que os formalistas russos também discutiram acerca do tema, resultando na publicação Poética do Cinema (Поэтика Кино, ${ }^{2}$ 1927).

O cinema é uma arte? Essa parece ser a questão que perpassa os artigos que compõem o livro. Para responder a tal pergunta, os membros da OPOIAZ (Sociedade para o Estudo da Linguagem Poética) mapearam e teorizaram aspectos da linguagem cinematográfica, sua essência e suas leis. Dentre os formalistas, Chklóvski desempenhou um papel central nas discussões em torno do cinema, embora esse interesse esteja baseado em uma relação complexa do teórico com a cinematografia, conforme veremos.

De modo geral, há dois aspectos do cinema que são muito frequentes nos estudos de Chklóvski: a dependência do efeito que se pretende gerar no espectador em relação ao enredo e o papel do enredo na unificação das ações e constituição de uma unidade coerente. $O$ foco na composição e nas leis da narrativa talvez seja uma explicação para a ausência do termo ostraniénie nos escritos de Chklóvski sobre cinema. Em seu texto publicado em 1923, "Cinematografia", encontramos um argumento, ainda que indireto, para essa lacuna:

2 Optamos pela utilização dos títulos com a grafia original a fim de facilitar a pesquisa por parte dos leitores interessados no tema. 
A teoria tradicional do verso enfatiza a violação da continuidade pela descontinuidade. O mundo contínuo é o mundo da visão. O mundo descontínuo é o mundo do reconhecimento.

O cinema é um filho do mundo descontínuo. O pensamento humano criou para si um novo mundo não intuitivo à sua própria imagem e semelhança. A partir dessa perspectiva, a imagem em movimento é um extraordinário fenômeno moderno - em sua magnitude, talvez, não em terceiro, mas em primeiro lugar. $^{3}$

Nessa conjuntura, a cinematografia está enraizada no domínio do reconhecimento, isto é, da percepção automática, tornando seu material os elementos articulados da realidade imediata, distinta da visão gerada pela obra de arte. Se, de um modo amplo, um efeito basilar do fenômeno artístico é a transformação do familiar em algo novo, o dispositivo cinematográfico lida com a limitação imposta por seu aparato principal, a câmera. Por isso, o cinema deveria buscar suas próprias potencialidades, embora, para Chklóvski, houvesse certo esgotamento do que as técnicas cinematográficas poderiam oferecer.

Nos estudos de Borís Eikhenbaum (1886-1959), no entanto, o cinema ganhou imediatamente o caráter de arte, portanto, meio capaz de gerar uma renovação no âmbito perceptivo. No artigo "Problemas de cine-estilística", para apresentar o cinema como arte, Eikhenbaum valeu-se justamente dos fundamentos do conceito ostraniénie na defesa de sua tese: "se a arte utiliza o cotidiano, é como material, com uma interpretação imprevista, deslocada, ou com um aspecto deliberadamente deformado (o grotesco)". ${ }^{4}$ O destaque nesse campo de percepção da realidade dado por Eikhenbaum o leva a identificar e analisar as questões significativas do cinema:

No cinema, o espectador se situa em algumas condições de percepção completamente novas que, até certo ponto, são opostas àquelas que se aplicam à leitura: vai-se do objeto, do movimento visível, à sua interpretação, sua designação, à elaboração de um discurso interior. O êxito do cinema se deve em parte a este novo tipo de trabalho do intelecto que não se verifica na vida corrente. ${ }^{5}$

3 SHKLOVSKY, 2008, p. 30. As traduções de citações foram realizadas pela autora do artigo.

4 EIKHENBAUM, 1998, p. 48.

5 Idem, p. 54. 
É interessante observar que a constituição do conceito ostraniénie tem a sua relevância ampliada quando o verificamos dentro do contexto histórico de sua gênese. Pensar o funcionamento das linguagens artísticas em um mundo em ebulição, que exigia novas reações ao impacto gerado pelas transformações políticas e sociais, é discutir a revolução artística imposta pelas demandas do momento, como lembra Galin Tihanov:

Embora o conceito de estranhamento possa ter diversas fontes em uma série de tradições críticas e filosóficas das quais Chklóvski pode ter tomado conhecimento (em geral, indiretamente), o fator de formação cuja contribuição foi crucial para o surgimento desse conceito é, sem dúvida, a Primeira Guerra Mundial. A guerra forneceu o solo propício onde uma visão de mundo materialista, focada na substância das coisas, pôde crescer e florescer em meio e a partir da cacofonia e do caos da aniquilação (e, em última instância, num protesto contra ela). ${ }^{6}$

É nessa chave de leitura que aproximamos os esforços de Chklóvski e Eisenstein na tentativa de constituição de novos meios de compreensão da imagem artística na e para a teoria das artes cujo ponto em comum passa pelas peculiaridades que circundam a ideia de ostraniénie. Não se trata aqui de buscar confluências restritas entre os dois pensadores, mas verificar de que forma o mundo em devir obrigava um outro modo de abordagem do mundo visível, além do limite do reconhecimento.

Diante disso, interessa-nos articular dois momentos específicos dos estudos de cada teórico: analisaremos os principais aspectos fundantes de ostraniénie de acordo com a perspectiva de Chklóvski. Em seguida, apresentaremos aspectos essenciais do programa pedagógico desenvolvido por Eisenstein para o curso de Direção Cinematográfica do Instituto Estatal Russo de Cinema (VGIK) e a inserção do conceito ostraniénie em suas aulas. Para concluir, consideraremos a importância dessas aproximações para o estudo das imagens artísticas na atualidade, sobretudo nos estudos interartes.

6 TIHANOV, 2018, p. 391. 


\section{Ostraniénie como técnica na arte}

O termo ostraniénie, muitas vezes traduzido como "estranhamento", "procedimento de singularização" ou "desautomatização", adquiriu considerável relevância na compreensão do objeto artístico ao longo do século XX. Os primeiros estudos de Chklóvski sobre o tema datam de meados de 1914, todavia, apenas em 1917, com a publicação do ensaio "Arte como procedimento", o termo foi sistematicamente apresentado.

A investigação desse aspecto da criação artística realizada por Viktor Chklóvski permitiu, primeiramente no âmbito da teoria literária, recolocar a questão da representação e a sua complexidade em relação aos componentes concretos que integram a obra, uma vez que os princípios de estruturação artística operam processos de percepção e significação, removendo seus elementos constitutivos da rede do convencional e estereotipado.

A dupla significação do conceito de percepção é um aspecto a ser considerado na formação artística ao admitir tanto a ideia de percepção automática quanto a geração de uma percepção sensorial e estética. A dinâmica apresentada por Chklóvski demonstra que o ponto central de seu pensamento teórico é delineado na tensão entre o modo de percepção sensorial de um referente e os atributos conhecidos de algo. Trata-se de um procedimento de criação e não uma técnica unilateral e estagnada:

A finalidade da arte é oferecer o objeto como visão e não como reconhecimento: o procedimento da arte é de ostranênie ${ }^{7}$ dos objetos, o que consiste em complicar a forma, em aumentar a dificuldade e a duração da percepção. $O$ ato da percepção é, na arte, um fim em si, e deve ser prolongado. $A$ arte é um meio de viver a feitura do objeto; aquilo que já foi feito não interessa em arte. ${ }^{8}$

\footnotetext{
7 Aqui respeitamos a opção de transliteração do tradutor.

8 CHKLÓVSKI, 2020, p. 161-162. Ressaltamos que embora exista a tradução já consagrada para o português do texto "Arte como procedimento", presente na coletânea Teoria da Literatura - os formalistas russos (Porto Alegre: Editora Globo, 1971), edição organizada por Dionísio de Oliveira Toledo, com prefácio de Boris Schnaiderman, optamos por utilizar, neste artigo, a recente tradução de David G. Molina, realizada diretamente do russo.
} 
A ênfase colocada por Chklóvski na forma da obra assinala o seu entendimento de que a recriação da vida por meio da arte está materializada em sua realidade substancial, em que as especificidades do mundo são transformadas artisticamente. Dessa maneira, é necessário pensar ostraniénie em sua pluralidade, isto é, como um conjunto de mecanismos estéticos explorados pelo artista a fim de desautomatizar a relação com o objeto artístico: "[...] a imagem não é um sujeito constante com predicados variáveis. Sua finalidade não é aproximar nossa compreensão do significado que ela contém, mas criar uma percepção especial do objeto, criar sua 'visão' e não seu 'reconhecimento'.9

Note-se que a materialidade primeira da imagem é a base dessas relações. Esse aspecto levou o autor a ampliar as possibilidades de aplicação do termo: "Eu, pessoalmente, acho que ostranênie existe praticamente onde quer que haja imagem". ${ }^{10}$ A imagem artística não é um referente permanente, mas, em sua continuidade, é gerada uma meta-estrutura semântica. Aqui o prefixo "meta" é entendido como algo que está "além de". Ao afirmar que "a arte é um meio de viver a feitura do objeto"," Chklóvski aponta a condição da arte de transpor os limites da superfície da forma e abrir outras conexões estéticas e conceituais. É essa condição que (re)configura a função do leitor, que não é mais aquele que recebe a informação, mas é introduzido pelo escritor na tessitura semântica do texto literário.

Fato significativo subjacente a essa linha de raciocínio é o entendimento de que "a feitura do objeto" é tão ou mais relevante que seu produto final, referindo-se a uma postura de sentir as coisas em sua essência para ressignificá-las. Esse importante aspecto parece-nos ser ressaltado, por exemplo, quando a pesquisadora Annie van den Oever, opta pelo termo "making strange" para traduzir o vocábulo ostraniénie

9 Idem, p. 168.

10 Idem, ibidem.

11 Idem, p. 162. 
[остранение] em língua inglesa. A estudiosa realça o processo de composição da obra, o que para nós parece ser um ponto basilar para o entendimento do termo.

Essa consciência do funcionamento da arte suscita uma relação única com o cotidiano: "O que chamamos arte, então, existe para retomar a sensação de vida, para sentir os objetos, para fazer da pedra, pedra". ${ }^{12}$ Desse modo, os dispositivos selecionados pelo artista para a composição da obra devem articular o referente, o conhecido, a fim de retirá-lo da automatização que deglute a percepção direta das coisas, levando a vida ao seu desaparecimento. Vale ressaltar que a ideia de sensação, conforme expõe Chklóvski, está embasada na articulação dos estímulos externos que conduzem o indivíduo a novos processos de apreensão do fenômeno estético.

Com efeito, ao longo dos anos em que se debruçou sobre este tema, Chklósvki analisou obras literárias e de outras linguagens, em que verificamos um conjunto de técnicas artísticas exploradas pelos artistas com o propósito de construir a expressividade da imagem. No deslocamento de forma para técnica, ostraniénie revela-se tanto no nível lexical quanto sintático, destruindo paradigmas usuais de representação da realidade.

Graças a esse aspecto diverso, ostraniénie tornou-se um recurso fulcral na abordagem das demais linguagens artísticas, sobretudo nos aspectos estéticos em torno do cinema, já que é da própria natureza cinematográfica o estabelecimento de uma tensão entre o registro de ocorrência, ou o que denominamos de realidade imediata, e a noção de representação artística. Nessa perspectiva, analisamos a obra fílmica na sua condição de provocar uma experiência que destrói a subjetividade imposta ao conteúdo direto, "tornando estranho" aquilo que poderia ser lido ou recebido de maneira óbvia.

A relevância dos atributos de ostraniénie, no âmbito das artes, levou outros artistas e teóricos a refletir sobre o tema, desencadeando pontos de vista divergentes e complementares acerca do conceito. Um exemplo dessa interlocução, nem

12 CHKLÓVSKI, 2020, p. 161. 
sempre uníssona, encontramos no interesse do cineasta-teórico Serguei Eisenstein pelo assunto, conforme pontua Valérie Pozner:

É evidente a atitude crítica de Eisenstein em relação ao conceito "ostraniénie", que ocupa um lugar central para a concepção de arte de Chklóvski e permeia todo o seu trabalho. O princípio de comparação morfológica não satisfaz Eisenstein, que coloca, a grosso modo, a culpa nos representantes da escola formalista de não considerarem o fator psicológico, ou melhor, psicanalítico. ${ }^{13}$

Ainda segundo Pozner, embora existam poucas evidências documentais de encontros entre ambos, não há como negar o impacto mútuo de suas produções. Tendo, para a autora, um maior interesse de Chklóvski pelas produções de Eisenstein. Como um exemplo desse entusiasmo, destacamos a biografia que o crítico escreveu sobre o cineasta, em 1973. Em ordem cronológica, a vida de Eisenstein é apresentada com tons ficcionais. O capítulo de abertura, intitulado "O nascimento de um herói", sintetiza bem essa forma de aproximação. Aliás o contexto de produção do livro é apresentado em entrevista concedida por Naum Kleiman a Oleg Aronson:

$\mathrm{Eu}$ não quero ser um filtro [do legado de Eisenstein]. Darei um exemplo, espero, preciso. Viktor B. Chklóvski, quando começou a escrever a biografia de Eisenstein, me ligou e falou que era um homem idoso e preguiçoso, que não gostava de ficar sentado em arquivos, mas não queria saber menos sobre o que o próprio Eisenstein escreveu. "Pedirei para você me trazer do arquivo tudo o que eles puderem dar", disse ele. E ele inclusive olhou em casa. Nós (Vladímir Boróvkov ainda participava do trabalho) fomos ao arquivo. Pegamos alguns materiais (cartas para a mãe, seus escritos da juventude etc), trouxemos para Chklóvski, ele revisou, e à tarde levamos de volta. Depois de algum tempo, ele de repente disse: estou cansado, "estou satisfeito", isto não é interessante para mim, não vou ler documentos, o que eu lembro, eu escrevo. Então frequentemente nós tínhamos conversas, ele me plantou a

13 POZNER, Valérie [ПОЗНЕР, Валери]. "Chklóvski/ Eisenstein - anos 20. História de um mal-entendido frutífero" ["Шкловский/Эйзенштейн - двадцатые годы. История плодотворного непонимания"]. Trad. de Nina Kulich [Нина Кулиш]. In: KinoZapiski, n. 46, 2000. Disponível em: < http://www.kinozapiski.ru/ru/article/sendvalues/586/>. Acesso em: 30 abr. 2020. 
seu lado e começou a inventar os problemas de Eisenstein. Eu nunca intervia, apenas falava, às vezes que, por exemplo, eu sabia de outra coisa, ou apontava alguma imprecisão. Ele escreveu o que quis. Naturalmente, em seu livro, há muitos dados não confiáveis. Muitos. [.... ${ }^{14}$

É possível identificar nessa relação certo distanciamento, mas que não pode ser limitado a essa constatação, já que, em parte, essa performance de Chklóvski se explica pelo emaranhado político em que Eisenstein e ele estão inseridos em diferentes momentos de suas vidas. Como lembra Pozner, quando se trata das questões teóricas "[...] aparecem, nos textos de Eisenstein, muito poucas indicações de que ele atenciosamente [...] leu os artigos de Chklóvski sobre literatura assim como sobre cinema". ${ }^{15}$

Investigar essa interação iniciada no período da vanguarda e que coincide com o estabelecimento do cinema, aponta-nos uma versão de leitura de mundo e suas conexões em que ostraniénie seria um meio de propor novas experiências qualitativas aos receptores de uma obra. Sem dúvida, não se trata de posicionamentos individuais, mas de lançar luzes para elementos básicos de um processo de ruptura histórica e estética. Dessa maneira, concordamos com a afirmação de que "Arte como procedimento" é um manifesto de sua época:

Dentro desse período e contexto [a Vanguarda], "Arte como procedimento", enfatizando a qualidade "estranha" do que é visto e seu impacto sobre a percepção, na verdade, dificilmente se sobressai como original. O fazer estranho ${ }^{16}$ é basicamente o que o novo meio [o cinema] em sua primeira fase "primitiva" produziu como experiência na maioria de seus espectadores. De muitas maneiras, ele proporcionou não só uma experiência forte e marcante, mas também uma experiência revolucionária compartilhada, no sentido restrito do termo. ${ }^{17}$

14 KLEIMAN, Naum [КЛЕЙMAH, Hаум]. Eisenstein Esquivo[Ускользающий Эйзенштейн]. [Entrevista concedida a Oleg Aronson [Олег Аронсон]. Isskustvo Kino (A arte do Cinema). Moscou, n. 10, outubro, 1998. Disponível em: <https://old.kinoart.ru/archive/1998/10/ n10-article14>. Acesso em: 04 mai. 2020.

15 POZNER [ПОЗHЕP]. Op. cit.

16 Aqui traduzimos o termo em consonância com a opção da autora em língua inglesa.

17 OEVER, 2010, p. 55. 
O estudo da variedade de método de construção traz, em sua gênese, um movimento, ainda que retórico, em direção ao contexto do modernismo, no âmbito das artes, e uma resposta aos aspectos objetivos que entravam na ordem do dia após as revoluções de 1917. Forçar o leitor ou espectador a lidar com as imprecisões de um mundo em construção, fazê-lo sair de uma abordagem automática dos elementos ao seu entorno, são algumas das demandas que dialogam diretamente com as dissonâncias do período. Como bem salienta Tihanov: "o estranhamento é uma técnica criada para auxiliar nesse processo, ao equipar o público leitor com a necessária agudeza de percepção e de reconhecimento". ${ }^{18}$

A dinâmica dos processos experimentados por ambos os autores, assim como suas estratégias construtivas, revela a riqueza do momento em que estão inseridos e a consciência social e estética do que almejam. Pensar as artes nesse movimento oferece-nos elementos para compreender que não havia espaço para uma leitura singular e homogênea do termo ostraniénie.

Outro legado relevante dessa estrutura prática e teórica, ainda que muitas vezes submetida às pressões políticas, foi a abertura para os estudos das linguagens artísticas sem que houvesse a delimitação por disciplinas, porém mantendo a análise das especificidades de cada esfera artística.

\section{O projeto pedagógico de Eisenstein}

Antes de analisar as reverberações do termo ostraniénie no projeto pedagógico de Eisenstein, parece-nos necessário oferecer algumas informações sobre a importância da docência na trajetória do cineasta, para fazermos a passagem das discussões estéticas e teóricas dos anos 1920 ao ambiente acadêmico e artístico da segunda metade dos anos 1930.

Em 1928, Eisenstein foi convidado a integrar a equipe de professores do Instituto Técnico de Cinematografia. O ingres-

18 TIHANOV, 2018, p. 392. 
so na atividade acadêmica coincidiu com o momento em que o cineasta intensificava a escrita de textos teóricos sobre a linguagem cinematográfica e aspectos estéticos estruturantes presentes em seus primeiros filmes. Em seus estudos, as propriedades do cinema são correlacionadas com aspectos de outras linguagens artísticas, caracterizando, já nesses escritos iniciais, uma abordagem interdisciplinar. A atividade docente foi interrompida em meados de 1929, quando o cineasta realizou uma viagem para estudar o cinema sonoro, passando por alguns países da Europa, Estados Unidos e México. Esse período de intenso contato com outras dinâmicas artísticas foi crucial para o amadurecimento das conviç̧ões de Eisenstein sobre a experiência cinematográfica e a relevância de propriedades cinemáticas anteriores ao cinema, que não se restringem ao dispositivo técnico.

Em 1932, Eisenstein retornou à docência ocupando o cargo de coordenador do curso de Direção Cinematográfica, no Instituto Estatal Russo de Cinema (VGIK). Com a nova atribuição, o cineasta-pedagogo recebeu a função de elaborar um programa pedagógico que contemplasse as exigências da reorganização do sistema educacional de acordo com as diretrizes do governo stalinista, em que, segundo o líder soviético, os esforços seriam direcionados "[...] para criar uma 'intelligentsia' de trabalhadores" ${ }^{19}$ Todavia, na prática, a reforma educacional para o ensino superior dispunha de outros objetivos efetivos: "[...] a ênfase estava na eficiência industrial, na disciplina e nos incentivos" ${ }^{20}$ Ainda segundo Sheila Fitzpatrick, ${ }^{21}$ os institutos técnicos também passaram por reformas significativas em relação às práticas pedagógicas vigentes desde a segunda metade dos anos 1920 com a finalidade de atender as exigências das indústrias e aperfeiçoar as habilidades de produção.

Provavelmente as imposições do período contribuíram para que o projeto pedagógico elaborado por Eisenstein contasse com várias versões. Em 1936, foi publicada a versão a que te-

19 FITZPATRICK, 2002, p. 214.

20 Idem, ibidem.

21 Idem, p. 217. 
mos acesso na atualidade. Nela há uma preocupação em estabelecer uma relação entre o conhecimento teórico e prático e apresentar justificativas consonantes com as determinações oficiais. Todavia, sobressai um frescor na implementação de ações didáticas que estimulam a resolução crítica e a construção de um caminho criativo particular. Ao elaborar suas estratégias no âmbito da aprendizagem, o cineasta-professor expandiu as indicações restritivas oficiais para as metodologias de ensino, criando certo espaço de autonomia para que os alunos pudessem experimentar, construir e desconstruir noções acerca do fazer arte, e, desse modo, tornarem-se cineastas capazes de propor soluções estéticas eficazes para a cinematografia.

A grade curricular apresentada por Eisenstein, com o intuito de responder a tal demanda, versa dos estudos das peculiaridades das diferentes linguagens artísticas às técnicas de fortalecimento físico. Os problemas práticos previstos no programa estão direcionados às discussões em torno da composição artística (organização do "caos criativo") e, de modo mais amplo, às áreas do conhecimento que dialogam com o trabalho do artista. Por se tratar de uma proposta interdisciplinar, os temas selecionados para cada semestre estavam direcionados à constituição de um leque de habilidades oriundas de objetivos específicos: "as áreas, seções e temas da disciplina de diretor são, portanto, consideradas como estágios de um único processo geral de desenvolvimento. Seu caráter específico é visto como uma progressão lógica, com saltos qualitativos entre as diferentes áreas e aspectos" ${ }^{22}$ A definição da sua proposta pedagógica também esclarecia que a comparação e o contraste entre as distintas ciências e linguagens acarretariam uma consistência estética para os futuros cineastas: "Em cada estágio, digressões nas fases correspondentes de outros ramos da atividade criativamente construtiva, que seguem os mesmos elementos e leis em outras esferas e áreas, são essenciais". ${ }^{23}$

22 EISENSTEIN, 2010, p. 74.

23 Idem. p. 75. 
Esses elementos e essas leis, que se movimentam na dinâmica de diferentes atividades artísticas, estão no centro das investigações desenvolvidas por Eisenstein, convertendo-se em fundamentação teórica básica de sua metodologia de ensino. Segundo o cineasta-pedagogo, os métodos acadêmicos mais tradicionais não seriam adequados para lidar com uma relação espiral do conhecimento advinda das múltiplas disciplinas, já que a academia usualmente preza pela fragmentação dos saberes.

A estruturação da modalidade de aprendizagem proposta para o curso de Direção Cinematográfica conduzia o aluno à responsabilidade crítica de analisar e incorporar heranças culturais ao repertório pessoal, o que permitiria ao discente armazenar experiências estéticas e abordá-las nas soluções artísticas encaminhadas a problemas delimitados, sobretudo nas questões advindas da composição. ${ }^{24}$

Em cada ano letivo, temas específicos foram selecionados e aprofundados, tanto em uma abordagem prática quanto teórica. Para dar conta desse plano didático de maneira profícua, especialistas de múltiplas áreas eram convidados a ministrar seminários para os alunos de Direção. Nesse contexto, é prevista a participação de Chklósvki ao longo do curso:

"[...] os estudantes passam por uma longa lista de 'especialistas' vivos e mortos. [...]

[...] Movendo-nos através das florestas da construção da história, dissecaremos com Aksiónov os esqueletos dos elisabetanos, ouviremos Dumas, pai, e Viktor Chklóvski sobre o esboço das estruturas da história, e sobre os métodos das obras de Weltmann". ${ }^{25}$

\footnotetext{
24 É pertinente, para pensarmos a atualidade das propostas eisensteinianas, salientar que a prática pedagógica presente no programa de direção cinematográfica assemelha-se ao que na contemporaneidade é denominado de metodologia ativa, em que os alunos cooperam mutuamente para a construção do conhecimento, além de serem motivados a expor ideias e construir a resolução de problemas propostos. Para exemplificar essa dinâmica, é possível conferir, em língua portuguesa, a transcrição de uma aula de Eisenstein intitulada "Sobre '0 capote' de Gógol", em tradução realizada pelo professor Paulo Peres. In: Revista USP, n. 2, jun/jul/ago. 1989. p. 71-84.
} 
Tendo em vista a leitura aqui proposta, salientaremos os tópicos previstos para o segundo ano, organizado a partir das ideias de criatividade e composição. Dentro dessas problemáticas, o cineasta-pedagogo destaca o que ele denomina "falácia da divisão mecânica na técnica externa e interna", assim como "falácia de uma síntese mecânica" ${ }^{26}$ que pode cercear o processo criativo. Quanto ao tema da composição, em primeiro lugar, está o "tratamento do conceito", seguido do "dispositivo para traduzir a especificação semântica e figurativa em uma imagem da ação" e da "lógica do desenvolvimento e simbiose composicional dos diferentes elementos da manifestação expressiva". ${ }^{27}$

Dentre os tópicos previstos na ementa, separamos as questões em torno da manifestação expressiva que apontam aspectos advindos do uso de ostraniénie na experimentação artística. As intervenções didáticas para o primeiro semestre do segundo ano foram divididas em quatro sessões: "a prática da manifestação expressiva", "a história do desenvolvimento da manifestação expressiva", "a teoria da manifestação expressiva" e "o processo da manifestação expressiva". Nesse enfoque, o estudo do processo criativo inicia com a abordagem dos elementos que compõem a mise-en-scène, seguido da análise dos meios em que o termo possui ressonâncias, da manifestação expressiva das plantas à psicologia humana. Cabe lembrar que o termo "movimento expressivo" foi usado por Eisenstein, em 1923, no artigo homônimo, escrito em parceria com Serguei Tretiákov (1892-1937) a fim de apresentar sistematicamente as bases do que seria um programa de treinamento para atores. Segundo os autores, o movimento expressivo deveria, na encenação teatral, revelar a função afetiva (no sentido daquilo que estimula determinada reação) na relação com o público ao provocar neste uma resposta à atuação do ator.

O entendimento do termo é ampliado, passando por uma série de metamorfoses e aprofundamentos de acordo com os

26 EISENSTEIN, 2010, p. 85.

27 Idem, ibidem. 
interesses explorados pelo cineasta no desenvolvimento de sua teoria. Assim o movimento expressivo surgiu centrado na potencialidade do corpo do ator, como um provocador de afetos e, a partir da segunda metade dos anos 1930, a lógica composicional também passou a ser abordada nessa perspectiva. A pluralidade subjacente ao conceito reafirma a visão intermidiática ${ }^{28}$ de Eisenstein da mesma maneira que este justifica seus estudos interdisciplinares ao propor a seus alunos a análise da manifestação expressiva na formação do pensamento filosófico contemplando escritos de Platão, Aristóteles, Espinoza, Freud, Pavlov dentre outros. O conceito surge nas experimentações teatrais, ganha densidade nas reflexões sobre o cinema e se expande para os estudos da composição das demais artes.

Vance Kepley, ao estudar a figura de Eisenstein pedagogo, enfatiza a importância da questão da expressividade artística na evolução de seus estudos, inclusive como base da relação entre as artes: "o problema pedagógico era isolar qualidades expressivas e determinar seu lugar em uma linguagem artística. Em termos práticos, os estudantes de cinema fariam melhor ao estudar romances, peças e outras formas expressivas do que assistir a filmes. ${ }^{29}$ Segundo Naum Kleiman, Eisenstein entende que a cinematografia possibilitou uma outra forma de compreender o conceito de realismo nas artes e nos meios de representação: "enquanto no teatro você tem a representação com um objeto, no cinema você tem a representação através do objeto".$^{30} \mathrm{~A}$ tarefa do cinema seria, portanto, provocar uma experiência estética que não se reduz ao visual; não é a repre

\footnotetext{
28 Aqui utilizamos a perspectiva dos estudos desenvolvidos por Irina 0. Rajewsky para quem a intermidialidade é "[...] um termo genérico para todos aqueles fenômenos que (como indica o prefixo "inter") de alguma maneira acontecem entre as mídias. "Intermidiático", portanto, designa aquelas configurações que têm a ver com um cruzamento de fronteiras entre as mídias e que, por isso, podem ser diferenciadas dos fenômenos intramidiáticos assim como dos transmidiáticos [...]". RAJEWSKY, Irina O. Intermidialidade, Intertextualidade e "Remediação" - uma perspectiva literária sobre a intermidialidade. Trad. de Thaïs Flores Nogueira Diniz e Eliana Lourenço de Lima Reis. In: DINIZ, Thaïs Flores Nogueira (Org.). Intermidialidade e estudos interartes: desafios da arte contemporânea. Belo Horizonte: Editora UFMG, 2012, pp. 15-45.

29 KEPLEY, 1993, p. 5.

30 KLEIMAN, 1998, p. 12.
} 
sentação de um fato ou o registro de um evento o elemento mais importante do cinema, mas o que é suscitado pela materialidade fílmica. Dessa forma, a narrativa é reduzida à sua essência. Semelhantemente, esse seria o trabalho dos grandes escritores: selecionar cenas específicas em que os estímulos provocam os "choques emocionais" que, na formação do todo, constituem o sistema total da obra, conforme o autor defende no texto "Cinema e os Clássicos":

[...] o trabalho com os clássicos não pode ser organizado dentro das linhas de empréstimo superficial, mas sim como uma questão de estudo de todos os elementos que constituem sua especificidade. Devemos interpretar seus signos e observar de que modo um elemento particular deveria se transformar em um novo, por meio de diferentes estágios no tempo e na categoria. Isso se aplica igualmente à técnica de representação de personagens e aos meios e métodos para incorporá-los. ${ }^{31}$

Eisenstein entende que a estrutura da obra de arte vai além da sua materialidade, portanto a única maneira de compreendê-la em sua plenitude é adentrando em suas camadas de significação (análise das estruturas profundas), abordagem que o semioticista V. V. Ivánov atribui originalmente ao cineasta: "Eisenstein, que, com efeito, foi o primeiro estudioso das estruturas profundas dos sistemas semióticos da arte [...]". ${ }^{32}$ Tais estruturas revelam a primazia das percepções visuais e sonoras na constituição do objeto artístico, elemento que coloca o espectador na condição de agente de constituição da obra de arte, tal como já havia evidenciado em relação à montagem de atrações no teatro e no cinema.

Não é a construção que está no centro da obra, mas o material de construção da obra. Desse modo, o segundo semestre letivo (quarto semestre do curso) é apresentado com a seguinte ementa: "O quarto semestre é dedicado a uma investigação da manifestação expressiva especialmente do ponto de vista da interação, e também como um complemento especial à sua

31 EISENSTEIN, 2010, p. 276

32 IVÁNOV, 2009, p. 69. 
manifestação na arte" ${ }^{33}$ É aqui que o conceito de movimento expressivo se amplia e encontra-se com o processo de percepção e a constituição da imagem; seja a imagem individual, seja a imagem da obra. Vejamos o modo de organização dos dois primeiros tópicos previstos para esse período letivo:

1. A imagem artística como a materialização formal do conteúdo e a imagem de uma ideia:

a) a causalidade social;

b) o produto criativo como a concretização da imagem do pensamento baseado em material particular;

c) o processo criativo como a prática de sua materialização.

2. A imagem da obra como a unidade da forma e do conteúdo:

a) Forma como a lógica do conteúdo, desenvolvida no pensamento emocional. Unidade na interpenetração entre os dois aspectos do pensamento em uma obra de arte integral;

b) o erro dos formalistas e a teoria de ostraniénie [desfamiliarização];

c) o ato criativo da percepção. ${ }^{34}$

Para Eisenstein, era relevante que seus alunos compreendessem os fenômenos artísticos e desenvolvessem uma espécie de consciência criativa baseada na percepção sensorial. Nesse ambiente de aprendizagem, a sala de aula torna-se um espaço em que novas esferas de sensações advindas da estrutura artística são testadas. Ao buscar métodos específicos para composições em que a complexidade visual está na base de um processo dinâmico entre criador e espectador, Eisenstein esperava que os futuros cineastas sob sua tutela fossem capazes de criar uma lógica singular de representação dos fenômenos culturais em que a organização da obra, por meio da interação de seus diferentes elementos, gerasse choques emocionais no espectador. É essa visão que surge em "A quarta dimensão do cinema", texto de 1929, em que o cineasta reafirma sua concepção de montagem não apenas como uma técnica específica, mas um sistema estético complexo que inclui uma espécie de "tempo interno" do espectador, ou, na síntese do

33 EISENSTEIN, 2010, p. 87.

34 EISENSTEIN, 2010, p. 89-90. 
cineasta, a construção cinematográfica organiza-se em torno de "[...] uma unidade complexa de manifestações de todos os seus estímulos". ${ }^{35}$

A montagem, que se dirige aos vários órgãos do sentido, não se prende ao que a combinação dos elementos já conhecidos pode gerar, mas, por meio da estrutura do pensamento sensorial, conecta-se às formas sensualmente percebidas que encaminham o espectador a uma relação dinâmica com a obra de arte. Esses elementos são aprofundados nos anos posteriores, conforme vemos no artigo "Sirva-se", publicado em 1932: "[...] a forma da montagem, como estrutura, é uma reconstrução das leis do processo de pensamento". ${ }^{36}$ Desse modo, para o cineasta-pedagogo, a verdadeira obra de arte não admitia uma relação passiva, o espectador deveria participar do processo de construção de imagem a partir do tema proposto na obra.

A ideia da quarta dimensão, portanto, fundamenta um propósito para a cinematografia que se estende às demais artes: a produção de novas formas expressivas. Eisenstein explana com seus alunos a síntese dialética gerada entre a realidade objetiva projetada na tela e a realidade da consciência a fim de compreender de que maneira uma genuína imagem artística é construída, abordando o que para ele seria um dos dilemas centrais do cinema, a questão da produção, o tratamento dado ao tema. Não por acaso, conforme lembra Oksana Bulgakowa, "Eisenstein não estava interessado na composição de uma peça, mas em seu efeito. Ele acreditava que a análise formal precisava ser acompanhada pelos estudos psicológicos". ${ }^{37}$

Diante disso, este parece ser um momento pertinente para pensarmos o que o cineasta considera como sendo "o erro dos formalistas": o distanciamento das questões psicológicas que envolvem a produção artística. Certamente essa temática não é tão simples como um recorte possa aparentar, mas aqui levantamos apenas um fio de um estudo mais amplo que a relação entre Eisenstein e os formalistas demanda. De qualquer modo, é relevante salientar que, diferente dos formalistas que

35 EISENSTEIN, 2002, p. 74.

36 Idem, p. 105.

37 BULGAKOWA, 2001, p. 39. 
dedicaram muitos estudos à composição do enredo cinematográfico, e até mesmo às limitações que o aparato técnico deveria enfrentar, Eisenstein, em suas aulas, não se prendia aos mecanismos narrativos, mas ao impacto que o "material estético" suscita no processo de construção da imagem artística.

O cinema, enquanto arte, operaria nas camadas "multissignificativas" estimuladas pela "escrita" da câmera, na articulação de espaço e tempo, nas escolhas de planos. São esses aspectos da linguagem cinematográfica que provocam as mudanças semânticas na matéria bruta registrada na película, levando ao estranhamento da realidade imediata por meio da montagem. Dessa maneira, uma possível verdade objetiva da realidade se romperia por meio do procedimento ostraniénie no momento em que o espectador se integra à forma artística.

Na visão que depreendemos dos estudos eisensteinianos, ostraniénie não seria apenas uma experiência estética, mas um caminho de aprofundamento por meio da interpretação que extrapola as referências externas. Por conseguinte, construiria uma realidade dinâmica própria às regras de cada obra, em que os significados psicológico e social estão estritamente interligados. O pensamento conceitual presente na base de construção da obra artística transformaria a realidade permitindo que o fenômeno da deformação da forma familiar conduzisse o espectador ao processo de construção da imagem.

Essa leitura torna-se muito fértil quando consideramos que muitas reflexões de Eisenstein foram amadurecidas no contexto do realismo socialista, em que as artes estavam subjugadas a um modelo oficial que prezava pela simplificação das formas e uma linguagem direta, capaz de atingir as massas. Junto a seus alunos, Eisenstein construiu estudos valorosos sobre o pensar a realidade além da objetividade como um mecanismo de construção estrutural. O multifacetado conceito de montagem exerce uma função essencial nesse processo de transformação do pensamento conceitual em imagem artística. Portanto a montagem seria um dispositivo capaz de levar o público a ser confrontado pela vida que poderia ser experimentada além da representação mimética. 


\section{Epílogo}

Longe de esgotar as possíveis conexões entre as temáticas abordadas por Eisenstein e Chklóvski, nosso objetivo foi expor a perspectiva de cada autor em relação à análise da imagem artística e, consequentemente, apontar as confluências entre os estudos apresentados capazes de originar um sistema de compreensão do fenômeno artístico. As correspondências articuladas nesse sistema e suas problemáticas encontram ressonâncias nos estudos interartes. Na condição de área de pesquisa, cuja base é o estudo das categorias estéticas que operam de modo interdisciplinar, verificamos, nos estudos interartes, a possibilidade de ampliarmos a leitura realizada por Eisenstein e Chklóvski das estratégias de criação artística (incluindo o anseio de explicar a experiência estética), uma vez que ambos os autores se preocuparam em elucidar o movimento das artes, dimensão que os encaminhou a necessidade de lidar com o cruzamento das fronteiras artísticas.

Não por acaso, as estratégias de criação em torno de ostraniénie são evocadas com frequência nos estudos das práticas artísticas contemporâneas. Na condição de dispositivo que propicia o rompimento da "estética material" de uma obra, mantém a sua atualidade ao mostrar que o ato de explorar os movimentos de ruptura na criação artística seria uma estratégia profícua para as artes ao longo do século XX. Esse enfoque também pode ser direcionado à observação dos meios intersemióticos de representação que questionam os conceitos de realidade e os processos já concebidos de produção artística.

Desse modo, ostraniénie configura-se como um estado de vir a ser nas artes, na vida, movimento reflexivo da potencialidade artística.

Na obra de Eisenstein, o estado de vir a ser é uma das condições da montagem enquanto mecanismo estético. Sua natureza dinâmica é capaz de revelar ou ocultar aspectos da imagem artística que se pretende construir, originando um movimento esférico que conduz o espectador a outras imagens e outros 
sistemas culturais. Origina-se, assim, um jogo associativo entre imagens geradoras de uma espécie de arca imagética oriunda de diferentes culturas e referências artísticas suscitadas na dinâmica da obra. Esse parece ser o motivo pelo qual o cineasta-pedagogo defende que a verdadeira ideia de cinematografia só pode ser concebida "[...] através da comparação crítica com as formas primitivas mais básicas do espetáculo [...]", ${ }^{38}$ já que o cinema, para Eisenstein, se instituiria como herdeiro das linguagens artísticas. Trata-se de um diálogo que não exclui as especificidades próprias de cada meio, mas potencializa aquelas eficazes para o impacto na percepção dos espectadores/leitores e, consequentemente, alteram o modo de ocorrência da experiência estética. Seria, portanto, possível entender a montagem como um dispositivo, presente nas diversas linguagens artísticas, apto a provocar ostraniénie.

Na condição de procedimento "visual" que conduz a constituição da imagem artística, ostraniénie conecta-se diretamente a processos de realização da imagem, do mesmo modo que atualiza questões na relação entre as artes e os dispositivos técnicos. É pertinente lembrar que o surgimento do cinema e a (re)posição das possibilidades técnicas no âmbito das artes desestabilizaram a herança mimética do século XIX, conduzindo, por exemplo, novas conexões estéticas oriundas do impacto da relação entre forma e conteúdo. Assim, as indagações que Eisenstein propõe a seus alunos acerca de ostraniénie estão estritamente articuladas com problemáticas relacionadas ao tratamento dado à forma artística e às leis de percepção sensorial na base da formação da imagem artística.

Por fim, nos escritos de Eisenstein direcionados à sua prática didática, não podemos desconsiderar a existência de uma tensão entre seus esforços para articular as demandas exigidas pelo regime stalinista e as suas convicções artísticas e estéticas. Desse modo, lidar com problemáticas em torno da concepção artística, ainda que dentro de um pequeno recorte, como aqui proposto, é entrar em contato com a multiplicidade de visões sobre um determinado tema e a tentativa de consti-

38 EISENSTEIN, 2002, p. 90 
tuição de recursos analíticos para interpelar o legado de artistas que não ficaram restritos a uma filiação teórica ou corrente crítica, mas que foram grandes leitores de sua época, assim como dos prováveis desdobramentos teóricos e artísticos advindos desses contextos.

\section{Referências bibliográficas}

ALBÈRA, François. Los formalistas rusos y el cine: la poética del filme. Trad. José Ángel Alcalde. Barcelona; Buenos Aires; México: Paidós, 1998.

BULGAKOWA, Oksana. Sergei Eisenstein: a biography. Trad. Anne Dwyer. Berlin; São Francisco: PotemkinPress, 2001.

CHKLÓVSKI, Viktor. "Arte como procedimento". Trad. David G. Molina. In: RUS - Revista de Literatura e Cultura Russa, São Paulo, v.10, n. 14, p. 153-176.

EIKHENBAUM, Boris. Problemas da cine-estilística. In: ALBÈRA, François. Los formalistas rusos y el cine - la poética del filme. Trad. José Ángel Alcalde. Barcelona; Buenos Aires: Paidós, 1998.

EISENSTEIN, Sergei. Writings, 1934-1947. Trad. William Powell. Londres: I. B. Tauris, 2010. Selected Works, v. 3.

EISENSTEIN, Sergei. A forma do filme. Trad. Teresa Ottoni. Rio de Janeiro: Jorge Zahar Ed., 2002.

FITZPATRICK, Sheila. Education and Social Mobility in the Soviet Union 1921-1934. Cambridge: Cambridge University Press, 2002.

IVÁNOV, V. V. Dos Diários de Serguei Eisenstein e outros ensaios. Trad. Aurora Fornoni Bernardini e Noé Silva. São Paulo: Editora da Universidade de São Paulo, 2009.

OEVER, Annie van den (ed.). Ostrannenie - on 'Strangeness' and the Moving Image. The history, Reception, and Relevance of a Concept. Amsterdã: Amsterdam University Press, 2010. 
SHKLOVSKY, Viktor. Literature and Cinematography. Trad. Irina Masinovsky. Champaign; Londres: Dalkey Archive Press, 2008.

TIHANOV, Galin. "Guerra, Revolução e Literatura Universal". Trad. Danilo Hora. In: CHKLÓVSKI, Viktor. Viagem Sentimental. Trad. Cecília Rosas. São Paulo: Editora 34, 2018. p. 390-401. IOFFE, Denis. "Pragmatika formalizma: k voprossu o "prieme ostreaneniia" i preodoleniia inertsii avtomatizma v russkom avangarde" ("Pragmática do formalismo: para a questão sobre o "procedimento ostraniénie" e a superação da inércia do automatismo na vanguarda russa"). In: Epokha "ostraneniia". Russkii formalizm i sovremennoe gumanitarnoe znanie. Moscou: Novoe literaturnoe obozrenie, 2017, pp. 325-332

Recebido em: 27/06/2020

Aceito em: 30/07/2020

Publicado em setembro de 2020 